\title{
Mesozoic mitogenome rearrangements and freshwater mussel (Bivalvia: Unionoidea) macroevolution
}

\author{
Elsa Froufe $\mathbb{C}^{1}$ - Ivan Bolotov $\mathbb{1}^{2,3} \cdot$ David C. Aldridge ${ }^{4}$ - Arthur E. Bogan ${ }^{5}$ Sophie Breton ${ }^{6} \cdot$ Han Ming Gan ${ }^{7}$. \\ Uthaiwan Kovitvadhi $^{8}$ - Satit Kovitvadhi ${ }^{9}$ - Nicoletta Riccardi ${ }^{10}$. Giulia Secci-Petretto ${ }^{1}$. Ronaldo Sousa ${ }^{11}$.

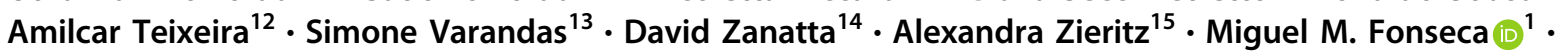 \\ Manuel Lopes-Lima ${ }^{1,16,17}$
}

Received: 1 February 2019 / Revised: 28 May 2019 / Accepted: 30 May 2019 / Published online: 14 June 2019

(c) The Author(s), under exclusive licence to The Genetics Society 2019

\begin{abstract}
Using a new fossil-calibrated mitogenome-based approach, we identified macroevolutionary shifts in mitochondrial gene order among the freshwater mussels (Unionoidea). We show that the early Mesozoic divergence of the two Unionoidea clades, Margaritiferidae and Unionidae, was accompanied by a synchronous split in the gene arrangement in the female mitogenome (i.e., gene orders MF1 and UF1). Our results suggest that this macroevolutionary jump was completed within a relatively short time interval (95\% HPD 201-226 Ma) that coincided with the Triassic-Jurassic mass extinction. Both gene orders have persisted within these clades for $200 \mathrm{Ma}$. The monophyly of the so-called "problematic" Gonideinae taxa was supported by all the inferred phylogenies in this study using, for the first time, the M- and F-type mitogenomes either singly or combined. Within Gonideinae, two additional splits in the gene order (UF1 to UF2, UF2 to UF3) occurred in the Mesozoic and have persisted for $\sim 150$ and $\sim 100 \mathrm{Ma}$, respectively. Finally, the mitogenomic results suggest ancient connections between freshwater basins of East Asia and Europe near the Cretaceous-Paleogene boundary, probably via a continuous paleo-river system or along the Tethys coastal line, which are well supported by at least three independent but almost synchronous divergence events.
\end{abstract}

\section{Introduction}

The tempo, timing and mode of evolution have attracted considerable debate among evolutionary biologists. Here we use a new approach using mitogenome rearrangements to investigate changes at the geological time scale in the speciose and imperilled freshwater mussels.

In many taxonomic groups, the gene arrangement within mitogenomes is highly conserved, e.g., many vertebrate groups share the same gene order (Pereira 2000). Other faunal groups, such as the Bivalvia, exhibit a number of different mitochondrial gene arrangements (e.g., Yuan et al. 2012), which are the result of different mechanisms such as

Supplementary information The online version of this article (https:// doi.org/10.1038/s41437-019-0242-y) contains supplementary material, which is available to authorized users.

Elsa Froufe

elsafroufe@gmail.com

Extended author information available on the last page of the article tandem duplication followed by gene loss (Boore 2000). Although local homoplastic arrangements have been identified in some invertebrate groups (e.g., Flook and Rowel 1995; Dowton and Austin 1999), complete gene orders generally remain unique and represent signatures with diagnostic value (Basso et al. 2017), providing a powerful signal for inferring ancient evolutionary relationships (Boore 2000).

Among freshwater mussels of the order Unionida, which spans about 900 species and represents the major bivalve radiation in the freshwater environment (Lopes-Lima et al. 2017a, 2018a), five mitogenome rearrangements have been described so far (Lopes-Lima et al. 2017b). Within the superfamily Unionoidea (Margaritiferidae+Unionidae), the mitochondria are furthermore unusual in that two highly divergent mtDNA molecules exist in males (Female or Fand Male or M-type) as a result of Doubly Uniparental Inheritance (DUI) (Zouros et al. 1994; Breton et al. 2009). This is in contrast to the vast majority of animal taxa, which inherit their mtDNA exclusively through the maternal lineage and thus exhibit only F-type mtDNA. In Unionoidea 
males, M-type mtDNA is restricted to the gonadal tissue inherited from the paternal lineage, and F-type mtDNA is present in all somatic tissues transmitted from the maternal lineage and also in female gonadal tissue (Breton et al. 2009; Froufe et al. 2016; Fonseca et al. 2016; Lopes-Lima et al. 2017b).

In recent decades, complete mitochondrial genome sequences have been published for a wide range of taxa, enabling reconstruction of shallow and deep phylogenies in both vertebrates and invertebrates (e.g., Jacobsen et al. 2014; Liu et al. 2016). However, the number of available mitogenomes for Unionida is low, particularly for M-type genomes (Froufe et al. 2016; Fonseca et al. 2016; LopesLima et al. 2017b; Huang et al. 2019). A further shortcoming is that published mitogenomes are restricted to only a few higher Unionida taxa, with no mitogenomes being available for several families and subfamilies. In fact, of the six recognized Unionida families (Lopes-Lima et al. 2014), published mitogenomes are essentially restricted to the Unionoidea (Unionidae+Margaritiferidae) with a distribution predominantly within the Northern Hemisphere. While some studies have questioned the monophyly of the Unionoidea (e.g., Combosch et al. 2017; Whelan et al. 2011) the most comprehensive recent studies, using either full mitogenomes (Huang et al. 2019; Wu et al. 2019) or hundreds of nuclear loci (Pfeiffer et al. 2019) support its monophyletic status. Moreover, mitogenome-based Unionida phylogenies reconstructed to date have been based on either F- or M-type mitogenomes (Froufe et al. 2016; Fonseca et al. 2016; Lopes-Lima et al. 2017b). Although in these studies the highly divergent F- and M-type mitogenomes recovered identical phylogenies, concatenated phylogenetic analyses of M- and F-type datasets would be expected to recover a more robust phylogeny.

The Unionidae is the most species-rich Unionida family, comprising 620 species in several subfamilies and distributed widely (Lopes-Lima et al. 2017a). However, phylogenetic relationships within and between Unionidae subfamilies are still contentious and different phylogenies have been resolved with different analysed markers (e.g., Lopes-Lima et al. 2017a; Bolotov et al. 2017a).

One of the least studied Unionidae subfamilies, the Gonideinae, has a scattered distribution in the Northern Hemisphere (Lopes-Lima et al. 2017a). Species in this subfamily have suffered major declines, and half of the assessed Gonideinae species are currently listed as Near Threatened or Threatened (IUCN 2019). Moreover, $70 \%$ of recognized Gonideinae species have either never been assessed or are listed as Data Deficient by the IUCN Red List (IUCN 2019), indicating an urgent need for research into this family's diversity, distribution and ecology.

Another outcome of the general lack of data on Gonideinae is their unresolved phylogeny. In fact, monophyly of this sub-family is disputed. The first molecular study to include the so-called "problematic" Gonideinae taxa (Graf 2002) only examined the type species, i.e., Gonidea angulata (Lea 1838). Subsequent studies included several additional Gonideinae taxa but the clade Gonideinae was never recovered as monophyletic (Graf and Cummings 2006; Whelan et al. 2011; Pfeiffer and Graf 2013). More recently, multi-marker and mitogenomic approaches have consistently recovered Gonideinae as monophyletic (Huang et al. 2013; Pfeiffer and Graf 2015; Fonseca et al. 2016; Froufe et al. 2016; Lopes-Lima et al. 2017a, 2017b). Bolotov et al. (2017a, 2017b) subsequently elevated one of the four Gonideinae tribes established by Lopes-Lima et al. (2017a), i.e., Pseudodontini, to the subfamily level (i.e., Pseudodontinae).

A good understanding of the evolutionary biogeography of the Gonideinae can be fundamental for reconstructing patterns of connections of freshwater systems through space and time on a global scale. Our knowledge in this respect is still far from complete. The first biogeographic scenarios developed using Unionida data (e.g., Starobogatov 1970; Banarescu 1991) proved highly inaccurate, as they were mostly descriptive and based solely on the (dis-)similarity between unionid faunas. Furthermore, these scenarios were generated at a time when unionid taxonomy was poorly resolved and included numerous paraphyletic higher-order taxa as well as nominal taxa, determined by shell shape rather than reliable indicators of true biological species (e.g., Bolotov et al. 2017a; Konopleva et al. 2017). Modern paleontology-based models seem to be much more reliable. Based on the fossil record from Vietnam, Schneider et al. (2013) developed the hypothesis of an independent development of Unionida faunas in the Yangtze and Mekong basins, at least during the entire Cenozoic. In addition, Van Damme et al. (2015) showed that the African Early Cretaceous Unionida are representatives of Asian/Eurasian taxa with the lack of Gondwanan elements, while the African Jurassic assemblages are distinctly related to those in Eurasia.

Recently, a first statistical biogeographic model for the Unionidae at the global level indicated that the Unionidae most likely originated in Southeast and East Asia in the Jurassic, with the earliest expansions into North America and Africa (since the Albian), following the colonization of Europe and India (Bolotov et al. 2017a). However, the Jurassic fossil record of western North America (for a review see Watters 2001) and Africa (Van Damme et al. 2015) indicate that these continents were colonized before the Cretaceous. Additionally, two species-rich monophyletic mussel radiations with an early Cenozoic or even pre-Cenozoic origin were discovered within the paleoMekong catchment (Bolotov et al. 2017a, 2017b). These findings revealed that the largest river systems (e.g., 
Mekong, Yangtze and Mississippi) may represent ancient evolutionary hotspots of freshwater mussels (Scholz and Glaubrecht 2004; Wesselingh 2007).

On the basis of the most comprehensive data set of mitogenomes sampled to date, including eight newly sequenced mitogenomes, this paper aims to improve our understanding of the higher-order phylogeny and classification of Unionidae by the following: (1) testing the monophyly of the poorly known Gonideinae subfamily using both full F- and M- mitogenomes and, for the first time, mitogenomes concatenated; (2) estimating macroevolutionary patterns in freshwater mussels of the Unionidae using, for the first time, a fossil-calibrated mitogenomic approach; (3) estimating the timing of major divergence events and comparing them to those of mitogenome rearrangements; and (4) developing an updated integrative approach to the systematics of Unionidae, on the basis of the mitogenomic results. This will allow the reconstruction of the potential origin and ancient radiations of the Unionidae and detect the most probable ancestral areas.

\section{Methods}

\section{Sampling, DNA extractions, sequencing, assembly and annotation}

One male specimen of Chamberlainia hainesiana, Microcondylaea bonellii, Pilsbryoconcha exilis and Monodontina vondembuschiana were dissected for sampling of gonadal (to recover M-type mtDNA) and mantle (to recover F-type mtDNA) tissues. DNA extractions followed Froufe et al. (2016). The complete $\mathrm{M}$ - and F-type mitogenome sequencing and assemblage followed Gan et al. (2014), while annotations were performed using MITOS (Bernt et al. 2013). The final limits of tRNA genes were rechecked with ARWEN (Laslett and Canbäck 2008). All F- and Mmitogenomes have been deposited in GenBank database under the accession numbers MK994770-MK994777 and were visualized using GenomeVx (Conant and Wolfe 2008).

DNA (NUC) and amino acid (AA) sequences of all mtDNA protein-coding genes (PCG), except ATP8 and the gender-specific open reading frames (M-ORF, H-ORF and F-ORF; Breton et al. 2011), were used in the phylogenetic analyses. The sequences of each gene were aligned using MAFFT software (version 7.304, Katoh and Standley 2013) and trimmed with GUIDANCE2 (Sela et al. 2015; see Froufe et al. (2016) for the parameters used).

The gene alignments were then concatenated, resulting in two alignments with the following length: 13449 aligned nucleotide positions and 3870 aligned amino acids positions +1889 aligned nucleotide positions from the rRNA genes. The optimal partitioning scheme for each alignment was selected using PartitionFinder v. 2.1.1 software (Lanfear et al. 2016) under the greedy algorithm with proportional branch lengths across partitions. The best substitution models of DNA and protein evolution for each partition were selected under the BIC ranking method (Schwarz 1978). The codon positions of the protein-coding genes and each rRNA were defined as the initial data blocks for the partitioning schemes search.

An additional data set was also created, concatenating both F- and M-type gene alignments, with the following length: 26780 aligned nucleotide positions and 7661 aligned amino acid positions +3797 aligned nucleotide positions from the rRNA genes. This alignment included 45 Unionida species plus Mytilus galloprovincialis as an outgroup (Table 1) using the same partitioning method and model selection as described above.

\section{Phylogenetic analyses}

All phylogenetic analyses were performed using both Maximum Likelihood (ML) and Bayesian Inference (BI) methods. ML analyses were performed using RAxML (v. 8.0.0, Stamatakis 2014) with 100 rapid bootstrap replicates and $20 \mathrm{ML}$ searches. The BI was applied using MrBayes v. 3.2.7a (Ronquist et al. 2012) with two independent runs $\left(10^{7}\right.$ generations with a sampling frequency of 1 tree for every 100 generations), each with four chains (3 hot and 1 cold). All runs reached convergence (average standard deviation of split frequencies below 0.01). The posterior distribution of trees was summarized in a $50 \%$ majority rule consensus tree (burn-in of $25 \%$ ).

\section{Divergence time estimates}

The time-calibrated mitogenomic phylogeny was reconstructed in BEAST v. 1.8.4 based on two reliable fossil calibrations (Supplementary Table 1) using a lognormal relaxed clock algorithm with the Yule speciation process as the tree prior (Drummond et al. 2006, 2012; Drummond and Rambaut 2007). Calculations were performed at the San Diego Supercomputer Center through the CIPRES Science Gateway (Miller et al. 2010). The sample of M-type mitogenomes was used as outgroup. Similar settings to each gene partition as in the MrBayes analyses were specified but using a simplified evolutionary model (HKY; see Bolotov et al. 2017a for details). Five replicate BEAST searches were conducted, each with $5 \times 10^{7}$ generations and a tree sampling every $5000^{\text {th }}$ generation. The $\log$ files were checked visually with Tracer v. 1.7 for an assessment of the convergence of the MCMC chains and the effective sample size of parameters (Rambaut et al. 2018). The chains in one run did not reach the convergence and were excluded, the 
Table 1 List of specimens analysed (based on Lopes-Lima et al. 2017a, 2017b), GenBank references, and country

\begin{tabular}{|c|c|c|c|c|}
\hline TAXON & CODE & F-type GenBank & M-type GenBank & Country \\
\hline \multicolumn{5}{|l|}{ UNIONIDA } \\
\hline \multicolumn{5}{|l|}{ UNIONIDAE } \\
\hline \multicolumn{5}{|l|}{ AMBLEMINAE } \\
\hline Lampsilis ornata & LamOrn & NC_005335 & - & USA \\
\hline Leptodea leptodon & LepLeo & NC_028522 & - & China (Introduced) \\
\hline Potamilus alatus & PotAla & KU559011 & KU559010 & China (Introduced) \\
\hline Quadrula quadrula & QuaQua & NC_013658 & FJ809751 & USA \\
\hline Toxolasma parvum & TaxPar & NC_015483 & - & USA \\
\hline Venustaconcha ellipsiformis & VenEll & FJ809753 & NC_013659 & USA \\
\hline \multicolumn{5}{|l|}{ GONIDEINAE } \\
\hline \multicolumn{5}{|l|}{ CHAMBERLAINIINI } \\
\hline Chamberlainia hainesiana & ChaHai & MK994770 & MK994771 & Thailand \\
\hline Sinohyriopsis cumingii & SinCum & NC_011763 & KC150028 & China \\
\hline Sinohyriopsis schlegelii & SinSch & NC_015110 & - & China (Introduced) \\
\hline \multicolumn{5}{|l|}{ GONIDEINI } \\
\hline Microcondylaea bonellii & MicBon & MK994772 & MK994773 & Italy \\
\hline Ptychorhynchus pfisteri & PtyPfi & KY067440 & - & China \\
\hline Solenaia carinata & SolCar & NC_023250 & KC848655 & China \\
\hline Solenaia oleivora & SolOle & NC_022701 & - & China \\
\hline \multicolumn{5}{|l|}{ LAMPROTULINI } \\
\hline Lamprotula leai & LamLea & NC_023346 & - & China \\
\hline Lamprotula scripta & LamScr & NC_030258 & - & China \\
\hline Potomida littoralis & PotLit & NC_030073 & KT247375 & Portugal \\
\hline Pronodularia japanensis & ProJap & AB055625 & AB055624 & Japan \\
\hline \multicolumn{5}{|l|}{ PILSBRYOCONCHINI } \\
\hline Pilsbryoconcha exilis & PilExi & MK994776 & MK994777 & Malaysia \\
\hline Monodontina vondembuschiana & PseVon & MK994774 & MK994775 & Malaysia \\
\hline \multicolumn{5}{|l|}{ UNIONINAE } \\
\hline Aculamprotula tientsinensis & AcuTie & NC_029210 & - & China \\
\hline Aculamprotula coreana & AcuCor & NC_026035 & - & South Korea \\
\hline Aculamprotula tortuosa & AcuTor & NC_021404 & - & China \\
\hline Anemina arcaeformis & AneArc & NC_026674 & - & China \\
\hline Anemina euscaphys & AneEus & NC_026792 & - & China \\
\hline Anodonta anatina & AnoAna & NC_022803 & KF030962 & Poland \\
\hline Cristaria plicata & CriPli & NC_012716 & - & China \\
\hline Cuneopsis pisciculus & CunPis & NC_026306 & - & China \\
\hline 'Lamprotula gottschei ${ }^{\text {'a }}$ & LamGot & NC_023806 & - & China \\
\hline Lanceolaria grayana & LanGra & NC_026686 & - & China \\
\hline Lanceolaria lanceolata & ArcLan & NC_023955 & - & China \\
\hline Lasmigona compressa & LasCom & NC_015481 & - & USA \\
\hline Lepidodesma languilati & LepLan & NC_029491 & - & China \\
\hline Nodularia douglasiae & NodDou & NC_026111 & - & China \\
\hline Pyganodon grandis & PygGra & NC_013661 & FJ809755 & USA \\
\hline Sinanodonta lucida & SinLuc & NC_026673 & - & China \\
\hline Sinanodonta woodiana & SinWoo & HQ283348 & KM434235 & China \\
\hline Unio crassus & UniCra & KY290447 & KY290450 & Poland \\
\hline Unio delphinus & UniDel & KT326917 & KT326918 & Portugal \\
\hline Unio pictorum & UniPic & NC_015310 & - & Poland \\
\hline Unio tumidus & UniTum & KY021076 & KY021073 & Poland \\
\hline Utterbackia imbecillis & UttImb & NC_015479 & - & USA \\
\hline Utterbackia peninsularis & UttPen & HM856636 & NC_015477 & USA \\
\hline \multicolumn{5}{|l|}{ MARGARITIFERIDAE } \\
\hline Margaritifera dahurica & MarDah & NC_023942 & - & China \\
\hline Margaritifera falcata & MarFal & NC_015476 & - & USA \\
\hline Pseudunio marocanus & PseMrc & KY131953 & KY131954 & Morocco \\
\hline \multicolumn{5}{|l|}{ MYTILIDA } \\
\hline Mytilus galloprovincialis & MytGal & AY497292 & AY363687 & Greece \\
\hline
\end{tabular}

${ }^{\mathrm{a} O r i g i n a l}$ identification 
other runs were compiled with LogCombiner v. 1.8.4 (Drummond et al. 2012) using an appropriate burn-in depending on the start of convergence of MCMC chains in each run. Most of ESS values were recorded as $>300$, with a few ESS values $>100$. The maximum clade credibility tree was obtained from the post-burn-in trees using TreeAnnotator v. 1.8.4 (Drummond et al. 2012).

\section{Ancestral gene order and ancestral area reconstructions}

TreeREx (Bernt et al. 2008) was used for inferring the most parsimonious putative ancestral gene orders and gene rearrangements along the obtained Unionidae F-haplotype phylogenetic sub-tree with the default settings (http://pa cosy.informatik.uni-leipzig.de/185-0-TreeREx.html).

Ancestral area reconstruction models were calculated for the Unionidae using three different approaches, i.e., Statistical Dispersal-Vicariance Analysis (S-DIVA), DispersalExtinction Cladogenesis (Lagrange configurator, DEC), and Statistical Dispersal-Extinction Cladogenesis (S-DEC) implemented in RASP v. 3.2 (Yu et al. 2015) following Bolotov et al. (2017a). Margaritiferidae were not used in this analysis due to the limited number of available mitogenomes. Four possible distribution areas of the in-group taxa were coded as follows: (A) Southeast Asia, (B) East Asia, (C) North America, and (D) Europe. From the input matrix, two geographically unreliable constrains (AC and AD) were excluded.

\section{Results}

\section{Mitogenome characteristics and gene arrangements}

All eight sequenced haplotypes include the 13 proteincoding genes (PCGs) typically found in metazoan mitochondrial genomes, the sex-specific ORF described for all Unionida mitogenomes with DUI system (Breton et al. 2009, 2011) and 22 transfer RNA (tRNA) and two ribosomal RNA (rRNA) genes (Fig. 1). As expected, the length of the four newly sequenced M-type mitogenomes is larger than the corresponding F-type (Breton et al. 2009), ranging from $16,267 \mathrm{bp}$ in $P$. exilis to $17,465 \mathrm{bp}$ in $C$. hainesiana, while the F-type ranged from $16,020 \mathrm{bp}$ in $M$. bonellii to 16,746 bp in $C$. hainesiana (Table 2). The $\mathrm{A}+\mathrm{T}$ content, and GC and AT skews are similar in all sequenced species in both $\mathrm{F}$ and $\mathrm{M}$ mtDNA types, averaging around 60\%, 37 $(+)$ and $-0.23(+)$, respectively (Table 2 ).

The gene arrangements of Microcondylaea bonellii, $P$. exilis and Monodontina vondembuschiana are identical to all Gonideinae mitogenomes available on GenBank (2018), named UF2 (Lopes-Lima et al. 2017b). However, $C$. hainesiana has a new and distinct gene arrangement, here named UF3 (Fig. 2).

\section{Phylogenetic analyses}

All the phylogenies inferred in this study that are based on $\mathrm{M}$ and $\mathrm{F}$ mitogenomes alone (i.e., not combined) support the monophyly of Gonideinae (Fig. 3). Moreover, the four tribes Chamberlainiini, Gonideini, Lamprotulini and Pilsbryoconchini, are also monophyletic in both M- and F-type trees (Fig. 3). The same results were obtained when using for the first time the $\mathrm{M}$ and $\mathrm{F}$ mitogenomes combined, despite the lower number of species (Fig. 4). The only unsupported result on the topology is seen in the relationship among the tribes Gonideini, Pilsbryoconchini and Lamprotulini in the ML AA data set (Fig. 4).

\section{Ancestral gene order and ancestral area reconstructions}

The TreeREx analysis indicated that the evolution of gene orders in the Unionidae F-type mtDNA is characterized by two independent events of tandem duplication and random loss (TDRL), with every ancestral gene order showing the highest consistency scores. The analysis suggests that the ancestral gene order for Unionidae F mitogenome is UF1, which is also found in the contemporary species of the subfamilies Ambleminae and Unioninae (Fig. 5). The fossilcalibrated mitogenomic analysis placed the split between the UF1 and MF1 gene orders in the Late Triassic (mean age $=208 \mathrm{Ma}, 95 \%$ high posterior density (HPD) 201-226 Ma) (Fig. 6).

The ancestral gene order of the Gonideinae species represented in our study is UF2, which results from a TDRL event of an mtDNA segment involving nad3, $\operatorname{trnH}, \operatorname{trn} A, \operatorname{trnS} 2$, trnS1, trnE, nad2, and trnM (Fig. 2 Box A). In UF2, the genes $\operatorname{trnH}, \operatorname{trnS} 1$, nad2 and trnM pertain to the original segment, while the remaining genes-nad3, $\operatorname{trn} \mathrm{A}, \operatorname{trnS} 2$, and $\operatorname{trnE}$-are present in the duplicated segment (Fig. 2 Box A). The fossilcalibrated model developed suggests that the UF1 and UF2 gene orders split near the Jurassic-Cretaceous boundary (mean age $=149$ Ma, 95\% HPD 138-162 Ma) (Fig. 6).

Finally, the UF3 gene order also arises after a TDRL event within Gonideinae (Fig. 2 Box B). It involved an mtDNA segment containing twelve genes: trnQ, trnC, trnI, $\operatorname{trnV}$, trnL2, nad1, trnG, nad6, nad4, nad41, atp8 and trnD. In UF3, the genes $\operatorname{trnC}, \operatorname{trnI}, \operatorname{trnV}, \operatorname{trnG}$, nad6, atp8 and $\operatorname{trn} D$ are retained in the original segment, whilst genes trnQ, trnL2, nad1, nad4 and nad41 were not lost in the duplicated one (Fig. 2 Box B). The fossil-calibrated model placed the split between the UF2 and UF3 gene orders in the Cretaceous near the Albian-Cenomanian boundary (mean age $=$ 102 Ma, 95\% HPD 77-124 Ma) (Fig. 6). 
Fig. 1 Gene maps of the F- and M-type mitochondrial genomes of Chamberlainia hainesiana, Microcondylaea bonellii,

Pilsbryoconcha exilis and Monodontina vondembuschiana. Genes positioned inside the circle are encoded on the heavy strand, and genes outside the circle are encoded on the light strand. Color codes: Small and large ribosomal RNAs (red), transfer RNAs (purple), FORF F-specific open reading frame (yellow), MORF M-specific open reading frame (yellow), PCGs genes (green)
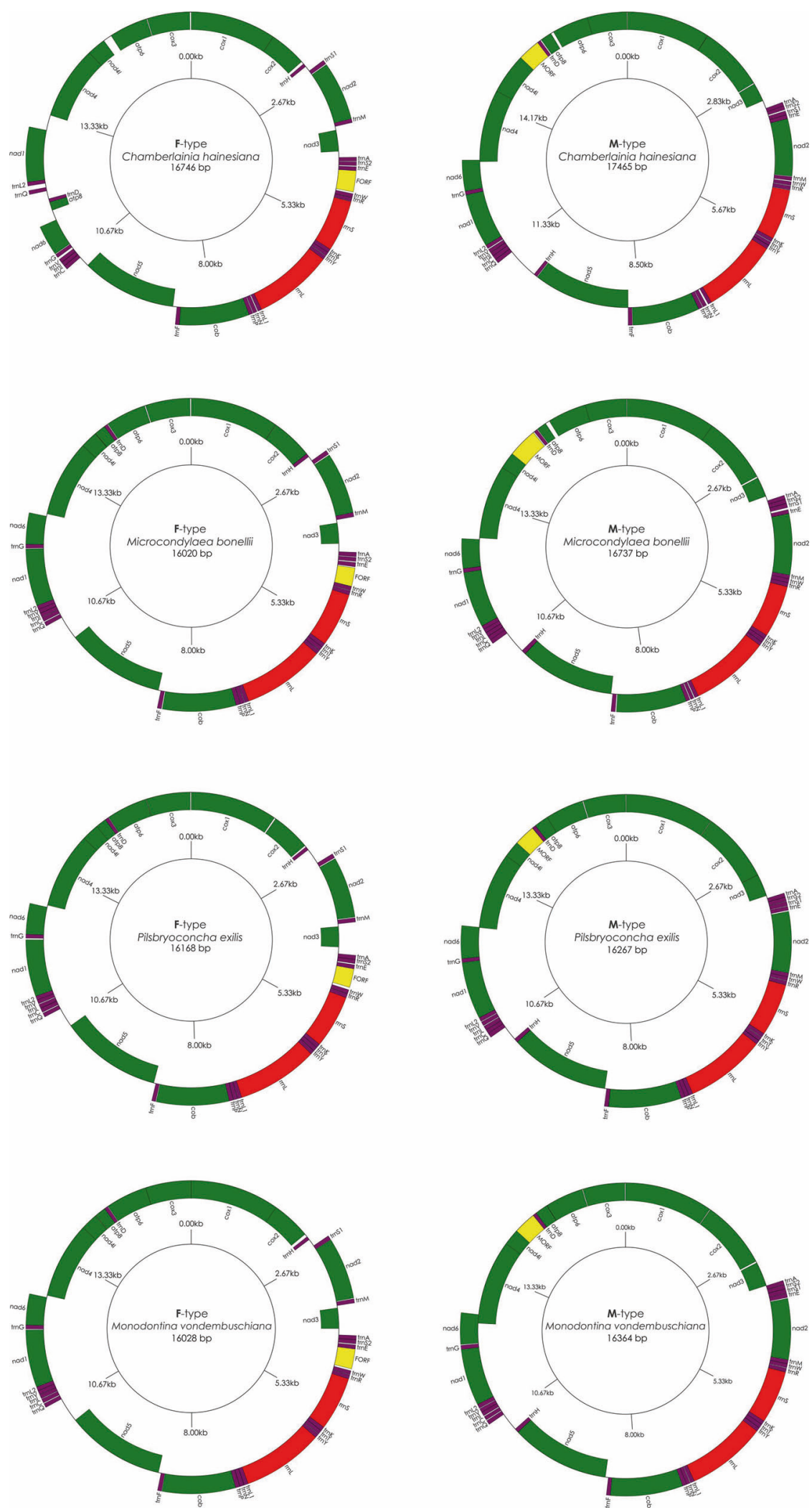

The combined ancestral area reconstruction model suggests that the Most Recent Common Ancestor (MRCA) of the crown group of the Ambleminae+(Gonideinae
+Unioninae) clade used to be widely distributed across the supercontinent of Laurasia (probability 100\%) (Fig. 7). The earliest split was between the Laurentian (Ambleminae) and 


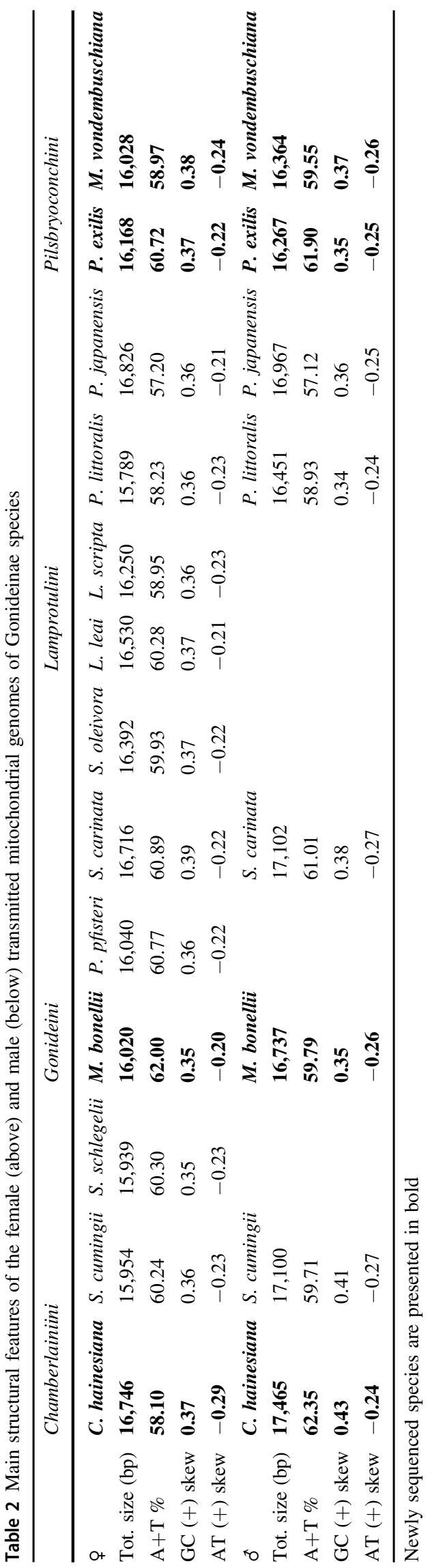

Eurasian (Gonideinae+Unioninae) taxa. This vicariance event is placed in the Late Jurassic (mean age $=159 \mathrm{Ma}$, 95\% HPD 155-170 Ma). Early diversification of the Gonideinae+Unioninae clade is placed within East Asia (probability 100\%; Fig. 7). The origin of the MRCA of this large clade (mean age $=149 \mathrm{Ma}, 95 \%$ HPD 138-162 Ma) and subsequent splitting into two subclades (mean ages of crown groups $=137$ and $106 \mathrm{Ma}$ and 95\% HPD 123-152 and 90-124 Ma for Gonideinae and Unioninae, respectively) most likely resulted from an intra-area radiation (probability $100 \%$ in each case) during the early Cretaceous. The Yangtze and Mekong unionid faunas have likely been separated since the Albian (mean ages $=95-102 \mathrm{Ma}$, 95\% HPD 77-124 Ma) (Fig. 7).

\section{Discussion}

\section{Phylogenetic patterns}

The new mitogenomic results presented here place the Pilsbryoconchina subtribe (previously under the Pseudodontinae as described by Bolotov et al. 2017a) as a subclade within the monophyletic Gonideinae in both the Mand F-type phylogenies. Our results are thus in agreement with the phylogeny recovered by Lopes-Lima et al. (2017a), which is also supported by morphological data. However, the recovered results contradict that of Bolotov et al. (2017a, 2017b), which suggested elevation of the Pseudodontini to the subfamily level.

Our results further indicate that the number of recognized subfamilies within the Unionidae is most likely lower than has been suggested by recent phylogenetic studies (Lopes-Lima et al. 2017a, 2017b; Bolotov et al. 2017a, 2017b). The mitogenomic results fully support three large subfamily-level clades: Ambleminae, Gonideinae and Unioninae. It is important to note that our analyses did not include members of the Parreysiinae and Rectidentinae. Nor did it include sequences of Modellnaia siamensis, the only species of the monotypic Modellnaiinae, which is characterized by a number of morphological and anatomical autapomorphies suggesting its separation within the Unionidae as a "phylogenetic relic" (Brandt 1974; Heard and Hanning 1978). Future studies including full mitogenomes of several taxa from Parreysiinae, Rectidentinae and Modellnaiinae are needed to fully resolve the higherlevel phylogeny of the global Unionidae.

Our results highlight that resolving the systematics of a large, species-rich clade such as the Unionidae is a complex task. Previous taxonomic schemes for the Unionidae included only two levels of family-group names, i.e., subfamilies and tribes (reviews: Lopes-Lima et al. 2017a; Bolotov et al. 2017a, 2017b). However, our whole 


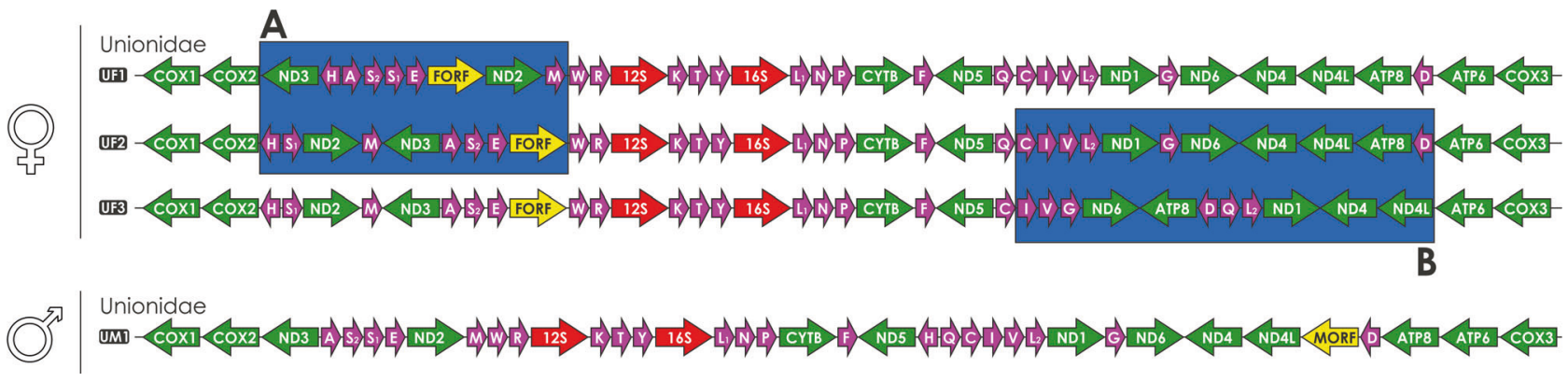

Fig. 2 Diagrams of the four distinct gene orders known in Unionidae to date. In the F-type, three gene orders are depicted: UF1, UF2 and UF3. In the male M-type lineage, the only Unionidae gene arrangement is shown: M-type 1 (UM1). Blue boxes highlight gene rearrangement region from UF1 to UF2 (Box A) and from UF2 to UF3 (Box B). Small and large ribosomal RNAs and transfer RNAs are depicted by one letter of the amino acid code; Arrow colour codes, follow Fig. 1

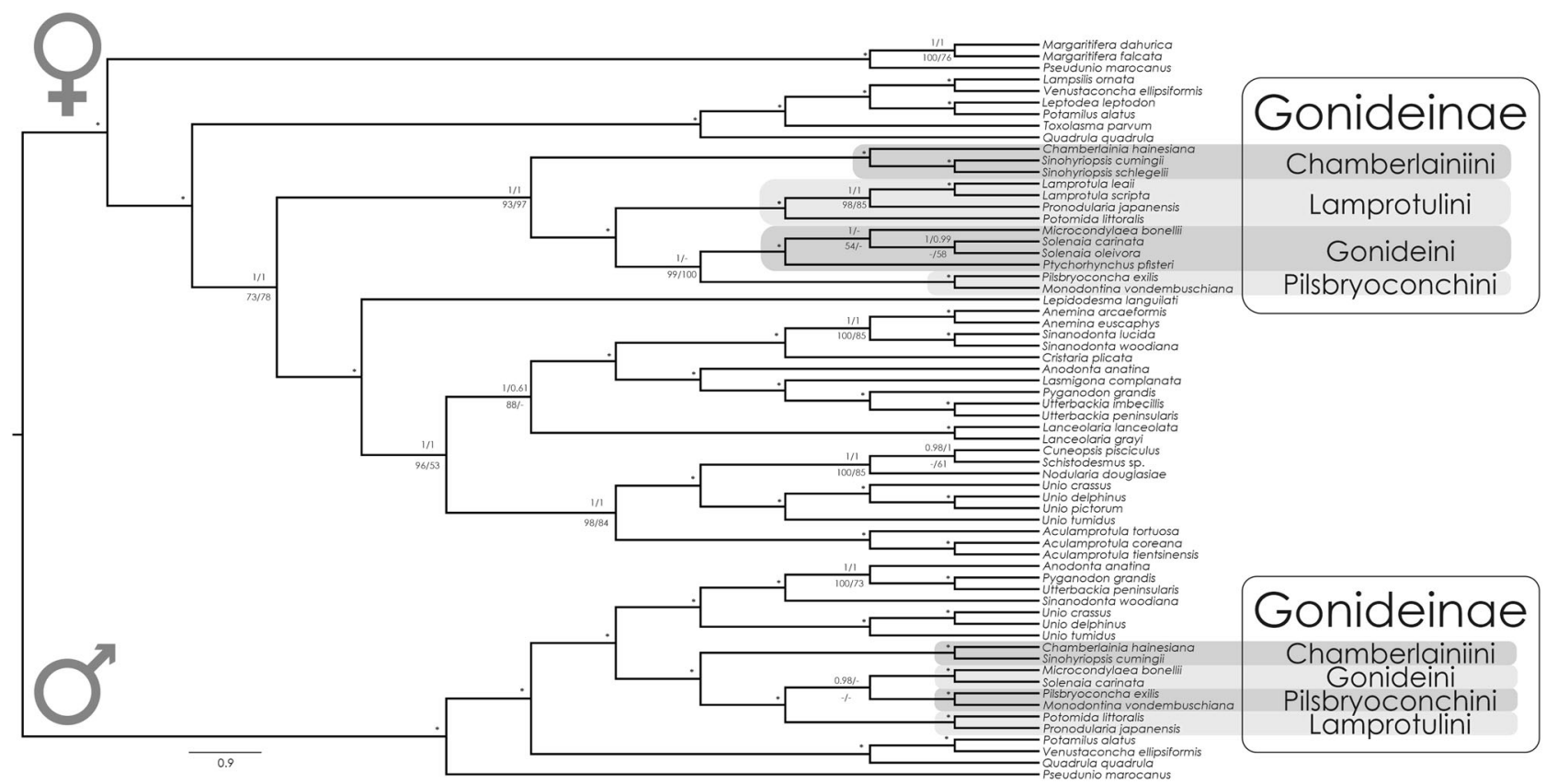

Fig. 3 Phylogenetic (BI-NUC) tree of Unionida estimated from 14 concatenated individual mtDNA gene sequences (12 protein-coding and 2 rRNA genes). Values for branch support are represented in the following order: (1) Bayesian posterior probabilities (PP) for BI-NUC tree, (2) Bayesian PP for BI-AA tree, (3) ML bootstrap support (BS) values for ML-NUC and (4) ML BS values for ML-AA tree. Maximum support values $(\mathrm{PP}=1, \mathrm{BS}=100)$ are represented by asterisks. Gonideinae subfamily and tribes are highlighted. For details see text. GenBank codes in Table 1

et al. 2019) shows strong similarity to our own findings in regard to the relationships of both families and subfamilies. Moreover, mitogenome data currently available suggest that the Unionidae comprise seven (Lopes-Lima et al. 2017a) or eight (Bolotov et al. 2017a) subfamily clades. Of these, the Gonideinae (encompassing Pseudodontinae), Unioninae (encompassing the Anodontinae) and Ambleminae were well supported in the mitogenomic results obtained herein, whilst the validity and placement of the Parreysiinae, Rectidentinae and Modellnaiinae clades are yet to be confirmed by mitogenomic analyses.

The largest monophyletic clades, within each subfamily, exhibiting significant morphological synapomorphies and he most recent nuclear-based Unionoida phylogeny (using hundreds of nuclear protein-coding loci; Pfeiffer 


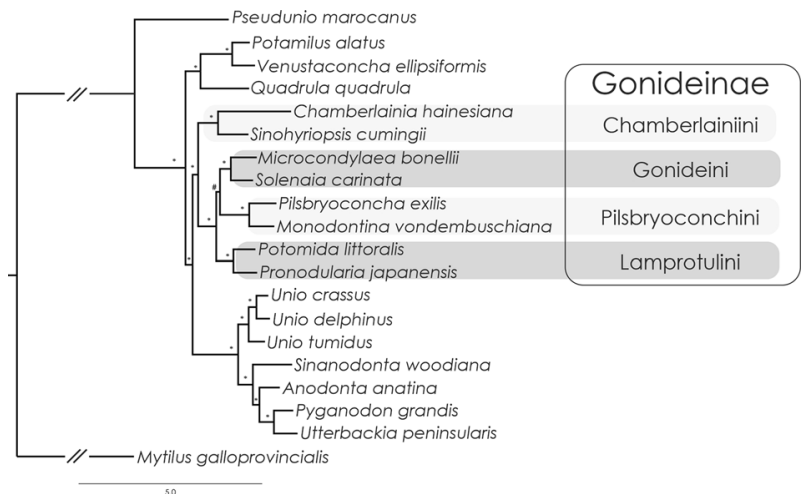

Fig. 4 Phylogenetic (BI-NUC) tree of Unionida estimated from 28 concatenated individual mtDNA gene sequences ( 24 protein-coding and 4 rRNA genes) of the first combined Female+Male concatenated data set. Maximum branch support values $(\mathrm{BI}-\mathrm{NUC} / \mathrm{BI}-\mathrm{AA} \mathrm{PP}=1$; ML-NUC/ML-AA BS = 100) are represented by asterisks, while \# represents the only non-supported branch by ML-AA tree. Gonideinae subfamily and tribes are highlighted. GenBank codes in Table 1

fully supported by the present mitogenomic results, are herein considered as tribes. Therefore, using these criteria, the Gonideinae comprise two tribes, i.e., Gonideini (trapezoidal to rectangular shells with none or only vestigial hinge teeth and tetragenous brooding type) and Chamberlainiini (round to oval shells, with a well-developed hinge structure and ectobranchous brooding type).

The subtribes represent smaller but distant clades within the tribes, comprising several genera or even a single highly divergent genus that usually does not reveal any unique synapomorphies but can be distinguished on the basis of molecular characters. Based on data available to date, including the present results, the Gonideini comprise at least five subtribes, i.e., Chamberlainiina, Gonideina, Lamprotulina, Pilsbryoconchina and Pseudodontina (Lopes-Lima et al. 2017a; Bolotov et al. 2017a, 2017b).

\section{Macroevolutionary patterns of the Unionidae}

The new mitogenomic analysis presented herein supports the hypothesis of an ancient Mesozoic origin and diversification of the Unionoidea (Taylor 1988; Ma 1996; Van Damme et al. 2015; Bolotov et al. 2016; Araujo et al. 2017; Bolotov et al. 2017a, 2017b). The new results indicate that the Late Triassic split between the Margaritiferidae and Unionidae coincided approximately with the Triassic-Jurassic extinction that was one of the largest mass extinction events in the Phanerozoic (Watters 2001; Hesselbo et al. 2002; Bogan and Weaver 2012; Percival et al. 2017; Smithwick and Stubbs 2018). The divergence event between the two families was associated with TDRL event leading to formation of the two stable mitochondrial gene orders, i.e., MF1 and UF1, which have persisted without changes for $200 \mathrm{Ma}$. However, there were at least two

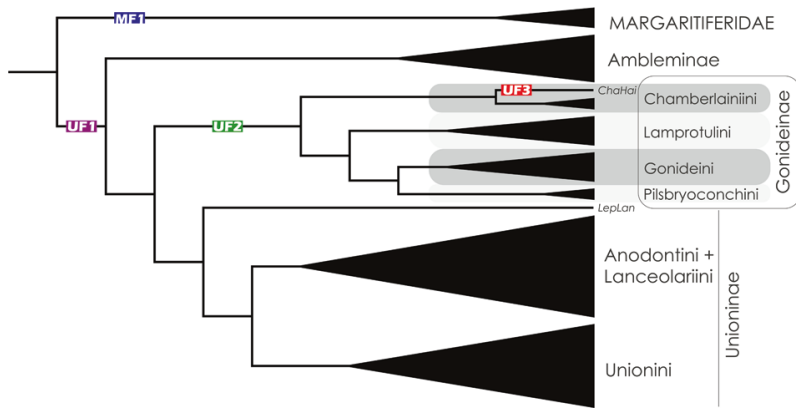

Fig. 5 Unionidae F-haplotype phylogenetic sub-tree (BI-NUC) used to infer the most parsimonious putative ancestral gene orders and gene rearrangements, mapped as MF1, UF1, UF2 and UF3 (see text for details). Margaritiferidae and all subfamily nodes were collapsed for visual purposes

additional Mesozoic splits in the mitochondrial gene order (i.e., UF1 vs. UF2 and UF2 vs. UF3) within the Unionidae, with UF2 and UF3 being restricted to a single subfamily, the Gonideinae. The first split coincided with the origin of this subfamily but the UF3 is a third, new and distinct gene arrangement derived from UF2 present in a single species, Chamberlainia hainesiana. These two mitochondrial gene orders have also persisted for long-term periods of $\sim 150$ and $\sim 100$ Ma for UF2 and UF3, respectively.

At least two splits in the mitochondrial gene order were associated with the origin of the MRCAs of large and diverse clades of family (Unionidae vs. Margaritiferidae) or subfamily (Unioninae vs. Gonideinae) levels. With respect to this evidence, these TDRL events could be considered progressive evolutionary innovations because they lead to formation of stable gene orders that have persisted within widely distributed and diverse clades for $\sim 150-200 \mathrm{Ma}$. As for the mitogenome gene order, our ancestral state analyses suggest UF1 (in the Unionidae) as the ancestral gene order, which is maintained in the subfamilies Ambleminae and Unioninae sensu lato (Fig. 6). Additionally, it indicates that the evolution of F-type mtDNA gene orders is characterized by two independent events of TDRL (Moritz et al. 1987; Boore 2000). One resulted in the evolution of UF2, present in the Gonideinae, and the other in UF3, within Gonideinae but restricted to Chamberlainia hainesiana. In contrast, all sequenced M-type Unionidae mitogenomes to date present the same gene order, i.e., UM1 (Lopes-Lima et al. 2017b) (Fig. 2). Possibly this could be explained by the higher natural selection pressure and/or due to the tight control of the DUI system on the paternal mitochondrial inheritance. In summary, our results reveal that each TDRL event was followed by the stable long-term persistence of a mitochondrial gene order through evolving lineages (or even a single lineage, although the Chamberlainia clade may actually be under-sampled) and corresponds to the first reliable mitogenomic evidence supporting the evolutionary 


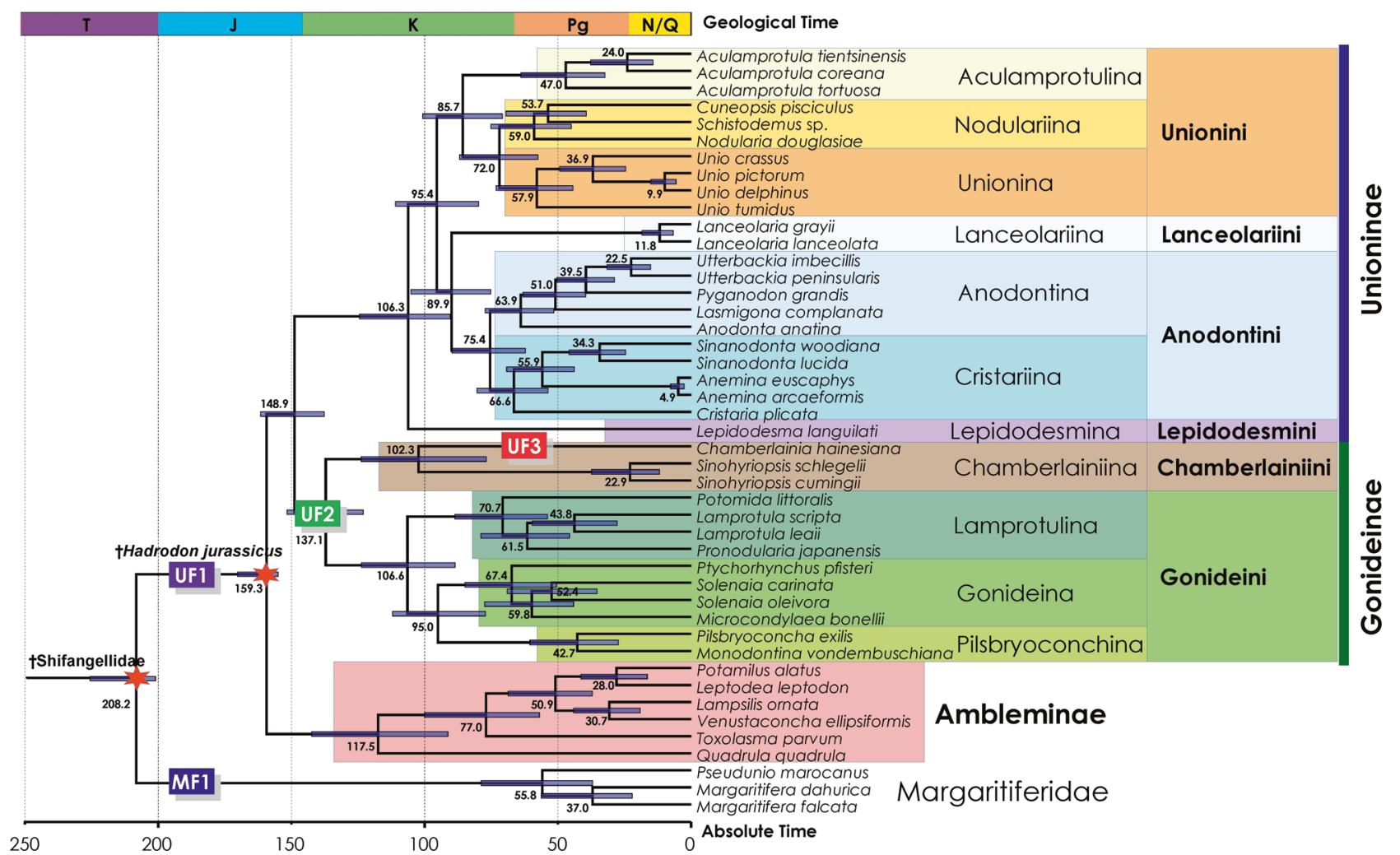

Fig. 6 Time-calibrated mitogenomic phylogeny, an example of threelevel classification scheme (subfamilies, tribes and subtribes) and evolution of the mitochondrial gene order in the Unionoidea. Fossilcalibrated ultrametric chronogram of the Unionoidea calculated under a lognormal relaxed clock model and a Yule process speciation implemented in BEAST and obtained for the complete mitogenome data set. The outgroup sample is not shown. Bars indicate $95 \%$

stasis in molecular traits of freshwater bivalves. However, this should be further explored using an expanded data set of mitochondrial genomes that may facilitate the understanding of how evolutionary rates have shifted across multiple genetic loci and how that corresponds to ecologically relevant traits.

\section{Diversification and Biogeography}

Combining our new fossil-calibrated mitogenomic analyses with robust ancestral area reconstruction provides new insights into early diversification patterns and biogeography of the Unionidae. According to our results, the Ambleminae $+($ Gonideinae+Unioninae) clade originated in the late Jurassic, with their MRCA distributed across Laurentia and Eurasia of the supercontinent of Laurasia. The split between the Ambleminae and Gonideinae+Unioninae clades was likely associated with a vicariance event driven by plate tectonics, i.e., the formation of the early Jurassic Transcontinental Laurasian Seaway (Bjerrum et al. 2001). The Ambleminae is an entirely Laurentian subfamily, which diversified primarily through radiation within the confidence intervals of the estimated divergence times between lineages (Ma). Black numbers near nodes are mean ages (Ma). Color labels indicate the mitochondrial gene order (MF1, UF1, UF2, and UF3). Red asterisks indicate fossil calibrations (Supplementary Table 1). Stratigraphic chart according to the International Commission on Stratigraphy, 2015

Mississippi drainage basin from the Early Cretaceous (Bolotov et al. 2017a). In this context, a peculiar Unionidae fauna from the Late Jurassic of western North America (Watters 2001) appears to be ancestral lineages and stem groups of the Ambleminae+(Gonideinae+Unioninae) clade. The Gonideinae and the Unioninae (Unionini, Anodontini, Lanceolariini, and Lepidodesmini) (Fig. 6) originated in East Asia, most likely via intra-area radiation within the paleo-Yangtze River system during the Cretaceous (Fang et al. 2009; Wang et al. 2018). The Southeast Asian Gonideinae taxa (Mekong basin) were separated via several vicariance events in the Albian - Cenomanian, which may indicate the drainage rearrangement of paleoriver systems of the Indochina Peninsula and surrounding terrains during this period (Wang et al. 2018). The mitogenomic results suggest ancient connections between freshwater basins of East Asia and Europe near the Cretaceous-Paleogene boundary, probably via a continuous paleo-river system or along the Tethys coastal line (Hou and Li 2018), and this is also depicted in the Margaritiferinae subfamily within Margaritiferidae (Lopes-Lima et al. 2018b). This pattern is well supported by at least three 
Fig. 7 Historical biogeography of the Unionidae. This combined scenario has been inferred from three different statistical modeling approaches (S-DIVA, DEC and S-DEC) based on the time-calibrated mitogenomic phylogeny (Fig. 6). Pie charts near nodes indicate probabilities of certain ancestral areas. Color circles on the tip nodes indicate the range of each species. Color labels indicate the mitochondrial gene order (UF1, UF2, and UF3)

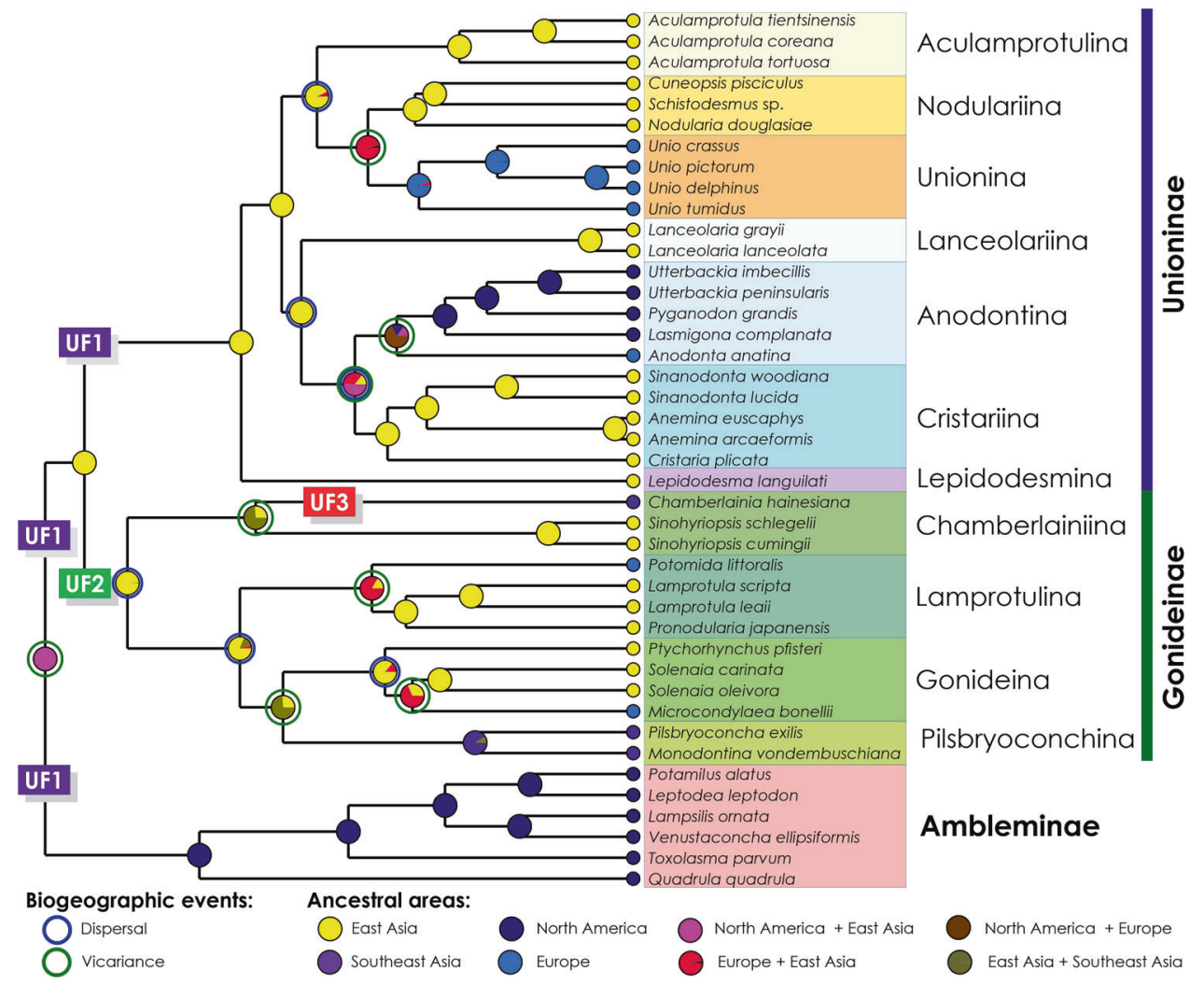

independent but almost synchronous divergence events: Potomida vs. Lamprotula and Pronodularia, Microcondylaea vs. Solenaia, and Unio vs. Nodularia and its relatives. During the same period, faunal exchange via the Beringian Land Bridge with subsequent vicariance events may also have started. The question of the origin of the family-clade, i.e., Unionidae, remains unanswered due to the lack of available mitogenomes of Parreysiinae and Rectidentinae, although combined COI, $28 \mathrm{~S}$ and $16 \mathrm{~S}$ data indicated that this family most likely originated within East or Southeast Asia (Bolotov et al. 2017a).

The new results presented herein support the hypothesis that several of the largest river basins on Earth may represent so-called ancient (long-lived) rivers, the Unionida faunas of which have existed throughout long-term periods comparable with geological epochs (Bolotov et al. 2017a; Lopes-Lima et al. 2018b). The mitogenomic results suggest that the MRCA of the entire Gonideinae+Unioninae clade may have originated within the paleo-Yangtze drainage basin. This indicates that the modern Yangtze may be a system of at least Late Jurassic origin and a stable refugium for very ancient, relic lineages that have existed for approximately $150 \mathrm{Ma}$. The unionid fauna of the paleoMississippi system seems to be of Early Cretaceous origin (mean age of the crown group in our model) that has diversified for at least $120 \mathrm{Ma}$. The paleo-Mekong fauna appears to be younger as it likely separated from the paleoYangtze fauna in the Albian - Cenomanian, and its two largest monophyletic unionid radiations may have had a Late Cretaceous or Paleocene origin (Bolotov et al. 2017a, 2017b). These results agree with the dating of divergence between two primary clades of the Southeast Asian cave spitting spiders that were separated at $\sim 55 \mathrm{Ma}$ by the paleo-Mekong River, which served as a biogeographic barrier (Luo and Li 2017).

\section{Systematics}

Based on the morphological evidence, we propose the putative MRCA of the Unionidae and Margaritiferidae as a new fossil family-level taxon in the Unionoidea.

Superfamily Unionoidea Rafinesque, 1820

Family $\uparrow$ Shifangellidae Bolotov, Bogan, Lopes-Lima \& Froufe fam. nov.

Type genus: $†$ Shifangella Liu \& Luo in Liu (1981)

Diagnosis: The Margaritiferidae and Unionidae are the most conchologically similar families to the $†$ Shifangellidae. However, $\uparrow$ Shifangellidae can be distinguished from the Margaritiferidae by having a weakly developed, narrow hinge plate (vs. typically well-developed and rather thick) and a shallow, smooth anterior adductor scar (vs. deep with arborescent-like striations), and from the Unionidae by an 
elongated Margaritifera-like shell with strongly concave ventral margin (vs. typically straight, rounded or slightly concave).

Distribution: Late Triassic, southwestern China (Sichuan).

Biology: This ancestral family likely had parasitic glochidial larvae similar to its descendants (ancestral state reconstruction, probability $100 \%$ ).

Comments: Synonymy of the genus $\dagger$ Palaeomargaritifera Ma 1996 (Middle Jurassic, China) with $\dagger$ Shifangella suggested by Fang et al. (2009) most likely erroneous because $†$ Palaeomargaritifera has a well-developed, thick hinge plate, strong pseudocardinal teeth and deep anterior adductor scar with arborescent-like striations supporting its original placement within the Margaritiferidae. The genus $\dagger$ Dianoconcha Guo, 1988 (Middle Jurassic, China), another synonym of $\dagger$ Shifangella proposed by Fang et al. (2009), differs by a subtrapezoid, elongate-elliptical or rhomboid shell. This feature together with a narrow hinge plate and an observable but shallow anterior adductor scar suggest that it most likely belongs to the Unionidae. With respect to their age and diagnostic features mentioned above, $\dagger$ Palaeomargaritifera and $\dagger$ Dianoconcha appear to be the MRCAs of the crown groups of the Margaritiferidae and Unionidae, respectively. The family-level placement of several unionoid genera described from the Early Jurassic of China (e.g., $\dagger$ Pseudomargaritifera Ma 1996 and $†$ Solenoides Ma 1996) is unclear and is in need of further revision; some of them might actually be members of the $†$ Shifangellidae.

\section{Conclusions}

All the phylogenies inferred in this study using, for the first time, both the $\mathrm{M}$ and $\mathrm{F}$ mitogenomes individually and combined support the monophyly of the so-called "problematic" Gonideinae taxa. Moreover, the new mitogenomic results place the Pseudodontinae, as previously described by Bolotov et al. (2017a), as a subclade within the monophyletic Gonideinae in both M- and F-type phylogenies. Additionally, the present work supports the hypothesis of an ancient Mesozoic origin and diversification of the Unionoidea and reveals that each TDRL event was followed by the stable, long-term persistence of a mitochondrial gene order through evolving lineages and corresponds to the first reliable mitogenomic evidence supporting the evolutionary stasis in molecular traits of freshwater mussels. Finally, we propose a new systematics framework with three infrafamilial levels (i.e., subfamilies, tribes, and subtribes) that better explains the evolutionary patterns within the Unionidae. Future application of the phylogenetic mitogenome-based approach outlined here to Parreysiinae, Rectidentinae and Modellnaiinae will be an important step to further resolve current taxonomic classification uncertainties within the Unionidae. Moreover, this study demonstrates the considerable potential for using comparative genomic techniques for unravelling patterns in the tempo, timing and mode of evolutionary processes.

\section{Data archiving}

Sequence data have been submitted to GenBank accession numbers: MK994770-MK994777.

Acknowledgements The authors wish to thank the Editor and the three anonymous reviewers for helpful remarks and suggestions that improved the quality of the manuscript. This research was developed under ConBiomics: the missing approach for the Conservation of freshwater Bivalves Project $\mathrm{N}^{\circ}$ NORTE-01-0145-FEDER-030286, cofinanced by COMPETE 2020, Portugal 2020 and the European Union through the ERDF, and by FCT through national funds (UID/Multi/ 04423/2019). FCT also supported MLL (SFRH/BD/115728/2016). The Russian Ministry of Education and Science (project no. 6.2343.2017/4.6), the Federal Agency for Scientific Organizations (project no. 0409-2015-0143), the Presidium of the Russian Academy of Sciences (scientific program no. 52), and the Russian Foundation for Basic Research, RFBR (project no. 17-45-290066) supported INB. Permits for fieldwork and sampling in Malaysia were issued by the Malaysian Ministry of Higher Education (FRGS/1/2015/WAB13/ $\mathrm{UNIM} / / 1)$.

\section{Compliance with ethical standards}

Conflict of interest The authors declare that they have no conflict of interest.

Publisher's note: Springer Nature remains neutral with regard to jurisdictional claims in published maps and institutional affiliations.

\section{References}

Araujo R, Schneider S, Roe KJ, Erpenbeck D, Machordom A (2017) The origin and phylogeny of Margaritiferidae (Bivalvia, Unionoida): a synthesis of molecular and fossil data. Zool Scr 46:289-307

Banarescu P (1991) Distribution and dispersal of freshwater animals in North America and Eurasia 2. In: Zoogeography of fresh waters, Aula-Verlag, Wiesbaden, Germany, p 519-1091

Basso A, Babbucci M, Pauletto M, Riginella E, Patarnello T, Negrisolo E (2017) The highly rearranged mitochondrial genomes of the crabs Maja crispata and Maja squinado (Majidae) and gene order evolution in Brachyura. Sci Rep 7(1):4096

Bernt M, Donath A, Jühling F, Externbrink F, Florentz C, Fritzsch G et al. (2013) MITOS: improved de novo metazoan mitochondrial genome annotation. Mol Phylogenet Evol 69:313-319

Bernt M, Merkle D, Middendorf M (2008) An Algorithm for inferring mitogenome rearrangements in a phylogenetic tree. In: Setubal JC, Stoye J, Stadler PF (eds) Comparative Genomics. Springer, Berlin, Heidelberg, p 143-157

Bjerrum CJ, Surlyk F, Callomon JH, Slingerland RL (2001) Numerical paleoceanographic study of the Early Jurassic Transcontinental Laurasian Seaway. Paleoceanography 16:390-404

Bogan AE, Weaver PG (2012) A new genus and new species of freshwater mussel from the mid Late Triassic rift lakes of eastern 
North Carolina (Bivalvia: Unionida: cf. Unionidae). Nautilus 126:105-112

Bolotov IN, Vikhrev IV, Bespalaya YV, Gofarov MY, Kondakov AV, Konopleva ES et al. (2016) Multi-locus fossil-calibrated phylogeny, biogeography and a subgeneric revision of the Margaritiferidae (Mollusca: Bivalvia: Unionoida). Mol Phylogenet Evol 103:104-121

Bolotov IN, Vikhrev IV, Kondakov AV, Konopleva ES, Gofarov MY, Aksenova OV et al. (2017a) New taxa of freshwater mussels (Unionidae) from a species-rich but overlooked evolutionary hotspot in Southeast Asia. Sci Rep 7:11573

Bolotov IN, Kondakov AV, Vikhrev IV, Aksenova OV, Bespalaya YV, Gofarov MY et al. (2017b) Ancient River Inference Explains Exceptional Oriental Freshwater Mussel Radiations. Sci Rep $7: 2135$

Boore JL (2000) The Duplication/random loss model for gene rearrangement exemplified by mitochondrial genomes of deuterostome animals. Springer, Dordrecht p 133-147

Brandt RAM (1974) The non-marine aquatic Mollusca of Thailand. Arch Moll 105:1-423

Breton S, Beaupre HD, Stewart DT, Piontkivska H, Karmakar M, Bogan AE et al. (2009) Comparative mitochondrial genomics of freshwater mussels (bivalvia: unionoida) with doubly uniparental inheritance of mtdna: gender-specific open reading frames and putative origins of replication. Genetics 183:1575-1589

Breton S, Stewart DT, Shepardson SP, Trdan RJ, Bogan AE, Chapman EG et al. (2011) Novel protein genes in animal mtDNA: A new sex determination system in freshwater mussels (Bivalvia: Unionoida)? Mol Biol Evol 28:1645-1659

Combosch DJ, Collins TM, Glover EA, Graf DL, Harper EM, Healy JM et al. (2017) A family-level tree of life for bivalves based on a Sanger-sequencing approach. Mol Phylogenet Evol 107:191-208

Conant GC, Wolfe KH (2008) GenomeVx: simple web-based creation of editable circular chromosome maps. Bioinformatics 24:861-862

Dowton A, Austin AD (1999) Evolutionary dynamics of a mitochondrial rearrangement "hot spot" in the hymenoptera. Mol Biol Evol 16:298-309

Drummond AJ, Ho SYW, Phillips MJ, Rambaut A (2006) Relaxed phylogenetics and dating with confidence. PLoS Biol 4:e88

Drummond AJ, Rambaut A (2007) BEAST: Bayesian evolutionary analysis by sampling trees. BMC Evol Biol 7:214

Drummond AJ, Suchard MA, Xie D, Rambaut A (2012) Bayesian Phylogenetics with BEAUti and the BEAST 1.7. Mol Biol Evol 29:1969-1973

Fang ZJ, Chen JH, Chen CZ, Sha JG, Lan X, Wen SX (2009) Supraspecific taxa of the Bivalvia first named, described, and published in China (1927-2007) Univ Kansas Paleontol Contrib New Ser 17:1-157

Flook P, Rowel H (1995) Homoplastic rearrangements of insect mitochondrial tRNA genes. Naturwissenschaften 82:336-337

Fonseca MM, Lopes-Lima M, Eackles MS, King TL, Froufe E (2016) The female and male mitochondrial genomes of Unio delphinus and the phylogeny of freshwater mussels (Bivalvia: Unionida). Mitochondrial DNA Part B 1:954-957

Froufe E, Gan HM, Lee YP, Carneiro J, Varandas S, Teixeira A et al. (2016) The male and female complete mitochondrial genome sequences of the Endangered freshwater mussel Potomida littoralis (Cuvier, 1798) (Bivalvia: Unionidae). Mitochondrial DNA Part A 27:3571-3572

Gan H, Schultz MB, Austin CM (2014) Integrated shotgun sequencing and bioinformatics pipeline allows ultra-fast mitogenome recovery and confirms substantial gene rearrangements in Australian freshwater crayfishes. BMC Evol Biol 14:19

Graf DL (2002) Molecular Phylogenetic Analysis of Two Problematic Freshwater Mussel Genera (Unio and Gonidea) and a Re-
Evaluation of the Classification of Nearctic Unionidae (Bivalvia: Palaeoheterodonta: Unionoida). J Moll Stud 68:65-71

Graf DL, Cummings KS (2006) Palaeoheterodont diversity (Mollusca: Trigonioida+Unionoida): What we know and what we wish we knew about freshwater mussel evolution. Zool J Linn Soc 148:343-394

Heard WH, Hanning GW (1978) Anatomical Features of Modellnaia siamensis (Mollusca, Bivalvia, Unionidae). Zool Scr 7:219-223

Hesselbo SP, Robinson SA, Surlyk F, Piasecki S (2002) Terrestrial and marine extinction at the Triassic-Jurassic boundary synchronized with major carbon-cycle perturbation: A link to initiation of massive volcanism? Geology 30:251-254

Hou Z, Li S (2018) Tethyan changes shaped aquatic diversification. Biol Rev 93:874-896

Huang X-C, Rong J, Liu Y, Zhang M-H, Wan Y, Ouyang S et al. (2013) The complete maternally and paternally inherited mitochondrial genomes of the endangered freshwater mussel solenaia carinatus (bivalvia: unionidae) and implications for unionidae Taxonomy. PLoS ONE 8:e84352

Huang X-C, Ouyang S, Ouyang J, Zhou S, Wu XP (2019) Towards a global phylogeny of freshwater mussels (Bivalvia: Unionida): Species delimitation of Chinese taxa, mitochondrial phylogenomics, and diversification patterns. Mol Phylogenetics Evol 130:45-59

IUCN (2019). The IUCN Red list of threatened species. version 20191. http://www.iucnredlist.org. Accessed Jan 2019

Jacobsen MW, Pujolar JM, Gilbert MTP, Moreno-Mayar JV, Bernatchez L, Als TD et al. (2014) Speciation and demographic history of Atlantic eels (Anguilla anguilla and A. rostrata) revealed by mitogenome sequencing. Heredity 113:432-442

Katoh K, Standley DM (2013) MAFFT Multiple sequence alignment software version 7: improvements in performance and usability. Mol Biol Evol 30:772-780

Konopleva ES, Bolotov IN, Vikhrev IV, Gofarov MY, Kondakov AV (2017) An integrative approach underscores the taxonomic status of Lamellidens exolescens, a freshwater mussel from the Oriental tropics (Bivalvia: Unionidae). Syst Biodiv 15:204-217

Lanfear R, Frandsen PB, Wright AM, Senfeld T, Calcott B (2016) PartitionFinder 2: new methods for selecting partitioned models of evolution for molecular and morphological phylogenetic analyses. Mol Biol Evol 34:772-773

Laslett D, Canbäck B (2008) ARWEN: a program to detect tRNA genes in metazoan mitochondrial nucleotide sequences. Bioinformatics 24:172-5

Liu X-Z (1981) On some newly discovered non-marine pelecypods from the Late Triassic Wuzhongshan Formation in Sichuan Basin. Bull Chengdu Inst Geol Min Resour Chin Acad Geol Sci 2:121-136

Liu Q-N, Xin Z-Z, Bian D-D, Chai X-Y, Zhou C-L, Tang B-P (2016) The first complete mitochondrial genome for the subfamily Limacodidae and implications for the higher phylogeny of Lepidoptera. Sci Rep 6:35878

Lopes-Lima M, Teixeira A, Froufe E, Lopes A, Varandas S, Sousa R (2014) Biology and conservation of freshwater bivalves: past, present and future perspectives. Hydrobiologia 735:1-13

Lopes-Lima M, Froufe E, Do VT, Ghamizi M, Mock KE, Kebapçı Üet al (2017a) Phylogeny of the most species-rich freshwater bivalve family (Bivalvia: Unionida: Unionidae): Defining modern subfamilies and tribes Mol Phylogenet Evol 106:174-191

Lopes-Lima M, Fonseca MM, Aldridge DC, Bogan AE, Gan HM, Ghamizi Met al (2017b) The first Margaritiferidae male (M-Type) mitogenome: Mitochondrial gene order as a potential character for determining higher-order phylogeny within Unionida (Bivalvia) J Moll Stud 83:249-252

Lopes-Lima M, Burlakova LE, Karatayev AY, Mehler K, Seddon M, Sousa R (2018a) Conservation of freshwater bivalves at the 
global scale: diversity, threats and research needs. Hydrobiologia 810:1-14

Lopes-Lima M, Bolotov IN, Do VT, Aldridge DC, Fonseca MM, Gan $\mathrm{HM}$ et al. (2018b) Expansion and systematics redefinition of the most threatened freshwater mussel family, the Margaritiferidae. Mol Phylogenet Evol 127:98-118

Luo Y, Li S (2017) Cave Stedocys spitting spiders illuminate the history of the Himalayas and southeast Asia. Ecography 41:414-423

Ma Q (1996) Revision of Mesozoic Margaritiferidae in China and their development. Acta Palaeontol Sin 35:408-429

Miller MA, Pfeiffer W, Schwartz T (2010). Creating the CIPRES Science Gateway for inference of large phylogenetic trees. In: 2010 Gateway Computing Environments Workshop (GCE), IEEE. $\mathrm{p} 1-8$

Moritz C, Dowling TE, Brown WM (1987) Evolution of animal mitochondrial DNA: relevance for population biology and systematics. Annu Rev Ecol Syst 18:269-292

Percival LME, Ruhl M, Hesselbo SP, Jenkyns HC, Mather TA, Whiteside JH (2017) Mercury evidence for pulsed volcanism during the end-Triassic mass extinction. Proc Natl Acad Sci USA 114:7929-7934

Pereira SL (2000) Mitochondrial genome organization and vertebrate phylogenetics. Genet Mol Biol 23:745-752

Pfeiffer III JM, Graf DL (2013) Re-analysis confirms the polyphyly of Lamprotula Simpson, 1900 (Bivalvia: Unionidae). J Moll Stud 79:249-256

Pfeiffer III JM, Graf DL (2015) Evolution of bilaterally asymmetrical larvae in freshwater mussels (Bivalvia: Unionoida: Unionidae). Zool J Linn Soc 175:307-318

Pfeiffer JM, Breinholt JW, Page LM (2019) Unioverse: a phylogenomic resource for reconstructing the evolution of freshwater mussels (Bivalvia, Unionoida). Mol Phylogenet Evol 137:114-126

Rambaut A, Drummond AJ, Xie D, Baele G, Suchard MA, Susko E (2018) Posterior summarization in Bayesian phylogenetics using tracer 1.7. Syst Biol 67:901-904

Ronquist F, Teslenko M, van der Mark P, Ayres DL, Darling A, Höhna $S$ et al. (2012) MrBayes 3.2: efficient Bayesian phylogenetic inference and model choice across a large model space. Syst Biol 61:539-542

Sela I, Ashkenazy H, Katoh K, Pupko T (2015) GUIDANCE2: accurate detection of unreliable alignment regions accounting for the uncertainty of multiple parameters. Nucleic Acids Res 43: W7-W14

Schneider S, Böhme M, Prieto J (2013) Unionidae (Bivalvia; Palaeoheterodonta) from the Palaeogene of northern Vietnam: exploring the origins of the modern East Asian freshwater bivalve fauna. J Syst Palaeontol 11:337-357
Scholz H, Glaubrecht M (2004) Evaluating limnic diversity: Toward a revision of the unionid bivalve Coelatura Conrad, 1853 in the Great Lakes of East Africa and adjacent drainage systems (Mollusca, Bivalvia, Unionidae). Zoosyst Evol 80:89-121

Schwarz G (1978) Estimating the dimension of a model. Ann Stat 6:461-464

Smithwick FM, Stubbs TL (2018) Phanerozoic survivors: Actinopterygian evolution through the Permo-Triassic and TriassicJurassic mass extinction events. Evolution 72:348-362

Stamatakis A (2014) RAxML version 8: a tool for phylogenetic analysis and post-analysis of large phylogenies. Bioinformatics 30:1312-1313

Starobogatov YI (1970) Fauna Mollyuskov i Zoogeograficheskoe Raionirovanie Kontinental'nykh Vodoemov Zemnogo Shara [Mollusk Fauna and Zoogeographical Partitioning of Continental Water Reservoirs of theWorld]. Nauka, Leningrad, Russia

Taylor DW (1988) Aspects of freshwater mollusc ecological biogeography. Palaeogeogr Palaeoclim Palaeoecol 62:511-576

Van Damme D, Bogan AE, Dierick M (2015) A revision of the Mesozoic naiads (Unionoida) of Africa and the biogeographic implications. Earth-Sci Rev 147:141-200

Wang P, Zheng H, Liu S, Hoke G (2018) Late Cretaceous drainage reorganization of the Middle Yangtze River. Lithosphere 10:392-405

Watters TG (2001) The Evolution of the Unionacea in North America, and its implications for the worldwide fauna. In: Bauer G, Wachtler K (eds) Ecology and evolution of the freshwater Mussels Unionoida. Ecological Studies, vol. 145. Springer-Verlag, Berlin, pp 281-307

Wesselingh FP (2007) Long-Lived Lake Molluscs as Island Faunas: A Bivalve Perspective. Springer, Dordrecht, pp 275-314

Whelan NV, Geneva AJ, Graf DL (2011) Molecular phylogenetic analysis of tropical freshwater mussels (Mollusca: Bivalvia: Unionoida) resolves the position of Coelatura and supports a monophyletic Unionidae. Mol Phylogenet Evol 61:504-514

Wu RW, Liu XJ, Wang S, Roe KJ, Ouyang S, Wu XP (2019) Analysis of mitochondrial genomes resolves the phylogenetic position of Chinese freshwater mussels (Bivalvia, Unionidae). ZooKeys $812: 23$

Yu Y, Harris AJ, Blair C, He X (2015) RASP (Reconstruct Ancestral State in Phylogenies): a tool for historical biogeography. Mol Phylogenet Evol 87:46-49

Yuan Y, Li Q, Yu H, Kong L (2012) The complete mitochondrial genomes of six heterodont bivalves (Tellinoidea and Solenoidea): variable gene arrangements and phylogenetic implications. PLoS ONE 7:e32353

Zouros E, Oberhauser Ball A, Saavedra C, Freeman KR (1994) An unusual type of mitochondrial DNA inheritance in the blue mussel Mytilus. Proc Natl Acad Sci USA 91:7463-7467

\section{Affiliations}

\section{Elsa Froufe $\mathbb{B}^{1} \cdot$ Ivan Bolotov $\mathbb{B}^{2,3} \cdot$ David C. Aldridge $^{4} \cdot$ Arthur E. Bogan $^{5} \cdot$ Sophie Breton $^{6} \cdot$ Han Ming Gan $^{7}$. Uthaiwan Kovitvadhi $^{8}$ - Satit Kovitvadhi ${ }^{9}$ - Nicoletta Riccardi ${ }^{10}$. Giulia Secci-Petretto ${ }^{1}$. Ronaldo Sousa ${ }^{11}$.

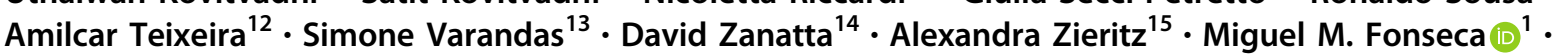 Manuel Lopes-Lima ${ }^{1,16,17}$}

1 CIIMAR/CIMAR - Interdisciplinary Centre of Marine and Environmental Research, University of Porto, Terminal de Cruzeiros do Porto de Leixões, Av. General Norton de Matos s/n, Matosinhos 4450-208, Portugal

2 IBIGER - Institute of Biogeography and Genetic Resources,
Federal Center for Integrated Arctic Research, Russian Academy of Sciences, Severnaya Dvina Emb. 23, Arkhangelsk 163000, Russian Federation

3 Northern Arctic Federal University, Severnaya Dvina Emb. 17, Arkhangelsk 163000, Russian Federation 
4 Department of Zoology, University of Cambridge, The David Attenborough Building, Pembroke Street, Cambridge CB2 3QZ, UK

5 North Carolina State Museum of Natural Sciences, 11 West Jones St., Raleigh, NC 27601, USA

6 Département de Sciences Biologiques, Université de Montréal, Montréal, QC H2V 2S9, Canada

7 Centre for Integrative Ecology, School of Life and Environmental Sciences, Deakin University, Geelong 3220 VIC, Australia

8 Department of Zoology, Faculty of Science, Kasetsart University, Bangkok 10900, Thailand

9 Department of Agriculture, Faculty of Science and Technology, Bansomdejchaopraya Rajabhat University, Bangkok 10600, Thailand

10 CNR - Institute for Ecosystems Studies, Verbania Pallanza (VB), Italy

11 CBMA - Centre of Molecular and Environmental Biology, Department of Biology, University of Minho, Campus Gualtar, Braga 4710-057, Portugal
12 CIMO/ESA/IPB - Mountain Research Centre, School of Agriculture, Polytechnic Institute of Bragança, Campus de Santa Apolónia, Apartado 1172, Bragança 5301-854, Portugal

13 CITAB/UTAD - Centre for Research and Technology of AgroEnvironment and Biological Sciences, University of Trás-osMontes and Alto Douro, Forestry Department, Vila Real 5000801 , Portugal

14 Biology Department, Institute for Great Lakes Research, Central Michigan University, Biosciences Bldg. 2408, Mount Pleasant, MI 48859, USA

15 School of Environmental and Geographical Sciences, University of Nottingham Malaysia Campus, Jalan Broga, Semenyih 43500, Malaysia

16 CIBIO/InBIO - Research Center in Biodiversity and Genetic Resources, University of Porto, Campus Agrário de Vairão, Rua Padre Armando Quintas 7, Vairão, Porto 4485-661, Portugal

17 SSC/IUCN - Mollusc Specialist Group, Species Survival Commission, International Union for Conservation of Nature, c/o The David Attenborough Building, Pembroke Street, Cambridge CB2 3QZ, UK 